\title{
The interactions between hemostasis and resistance training: a review
}

This article was published in the following Dove Press journal:

International Journal of General Medicine

8 March 2012

Number of times this article has been viewed

\section{Dahan da Cunha \\ Nascimento ${ }^{1-3}$ \\ Frederico Ribeiro Neto ${ }^{2}$ \\ Frederico Santos de \\ Santana ${ }^{1,2}$ \\ Renato André Sousa da \\ Silva ${ }^{1,4,5}$ \\ Leopoldo dos Santos-Neto ${ }^{6,7}$ \\ Sandor Balsamo $1,2,6$ \\ 'Physical Education Department, UNIEURO University Center, Brasília, DF, Brazil; ${ }^{2}$ GEPEEFS (Resistance training and Health Research Group), Brasília, DF, Brazil; ${ }^{3}$ Faculty of Physical Education, University of Brasília, Brasília, DF, Brazil; ${ }^{4}$ Center of Excellence in Medicine of Exercise (CEMEx) Brasília, DF, Brazil; ${ }^{5}$ Postgraduate Program on Physical Activity and Health, Catholic University of Brasília-UCB, Taguatinga DF, Brazil; ${ }^{6}$ Graduation Program - Medical Sciences Faculty, University of Brasília, Brasília, DF, Brazil; ${ }^{7}$ General Internal Medical Center - University Hospital Brasília, University of Brasília, Brasília, DF, Brazil}

Correspondence: Dahan da Cunha Nascimento

Department of Physical Education, University Center UNIEURO, Av. Das Nações, Trecho 0, Conjunto 5 - Brasília, DF, Brazil 70910-900

Tel +55 6I 8I48 0584

Email dahanc@hotmail.com
Abstract: Physical inactivity is considered a risk factor for cardiovascular disease and is strongly associated with changes in arterial structure. Regular physical activity and exercise contributes to the prevention of coronary artery disease. Therefore, cardiovascular and resistance training improve hemostatic parameters and promote a less thrombotic blood profile. This review highlights the studies, mechanisms, and outcomes relating to the effectiveness of resistance training on the process of hemostasis. The Pubmed, Scopus, Medline, Scielo, Lilacs, Ibecs, and Cochrane databases were used to locate the original articles. Seventeen studies were found during the research process. Of these, ten articles were excluded. Those protocols using a high volume of training for young adults showed a greater fibrinolytic response, and training protocols with intensities above $80 \%$ of 1 maximum repetition showed an increased platelet activity. In subjects with coronary artery disease, just one session of resistance training resulted in improvement in the fibrinolytic system (tissue plasminogen activator) without raising potential thrombotic markers.

Keywords: resistance training, blood coagulation, fibrinolysis

\section{Introduction}

"Hemostasis," defined as the balance between the processes of coagulation and fibrinolysis, ${ }^{1}$ is commonly investigated with regard to its clinical and prognostic relevance to cardiovascular disease. ${ }^{2}$ Smoking, ${ }^{3}$ hypertension, ${ }^{4}$ diabetes mellitus, ${ }^{5}$ and physical inactivity are considered risk factors and are strongly associated with changes in blood morphology, ${ }^{6}$ including significant effects on the hemostatic system, coagulation, fibrinolysis, platelet activation, vascular endothelial function, and the risk of venous and arterial thrombosis. ${ }^{7}$ Endothelial function is crucial in the regulation of vagal tone modulation, inflammation, platelet aggregation, and coagulation. ${ }^{8}$ In contrast, regular physical activity is associated with the prevention of cardiovascular disease risk factors and its effects are considered similar in magnitude $(\sim 30 \%)$ to pharmacological strategies. ${ }^{6}$

In this context, cardiovascular training promotes significant acute and chronic effects on hemostasis balance and contributes to a less thrombotic blood profile. ${ }^{9-11}$ However, most published studies present an exercise program consisting of only aerobic exercises. Both resistance training and aerobic training demonstrate positive effects on health and the prevention of diseases related to physical inactivity. ${ }^{12,13}$ However, there are limited studies investigating the effects of resistance training on coagulation and fibrinolysis.

Thus, the review highlights the studies, the mechanisms, and the outcomes that relate the effectiveness of resistance training to the process of hemostasis. 


\section{Methods}

For the review, databases from 1990 to 2011 (Scopus [1990-2011], ${ }^{14}$ MEDLINE $^{\circledR}$ [2008-2011], ${ }^{15}$ SciELO [1990-2011], ${ }^{16}$ LILACS [1990-2011], ${ }^{17}$ IBECS $[1990-2011],{ }^{18}$ and the Cochrane Library $[1990-2011]^{19}$ ) were used to locate the original articles. The last search was conducted on March 27, 2011. For a search of the references related to resistance training, we used the following terminology registered in the MeSH database: ${ }^{20}$ "resistance training", "strength training", and "resistance exercise" associated with "hemostasis," "blood coagulation factors," "platelet activation," "blood platelet count," "blood platelet counts," "blood viscosity," "blood platelets," "blood clotting," "platelet count," "platelet adhesiveness," "fibrinolysis," "beta-thromboglobulin," "thrombinantithrombin complex," "fibrinogen," "hemorheology," "tissue plasminogen activator," "plasminogen activator inhibitor 1," "Factor VIII/FVIII," "thrombin" and "fibrin fragment D" (for the abbreviations of terms, see Table 1). Once the abstracts were reviewed, complete versions of articles that met the criteria noted below were obtained. The contributing authors and the impact factors of the journals in which articles were published were noted and the study design, methodology, and clinical relevance were assessed. The five criteria for inclusion and exclusion of the studies were as follows:

1. Presented only the short-term and long-term effects of resistance training on markers of coagulation or fibrinolysis (beta-thromboglobulin, fibrinogen, thrombinantithrombin complex, tissue plasminogen activator, plasminogen activator inhibitor 1, platelet aggregation and factor VIII/FVIII).

2. Published in English.

3. Sampled ages from 18 to 90 years, of either gender and in any medical condition.

4. Had any of the following hemostatic factors in the article title, keywords, or methodology: beta-thromboglobulin, fibrinogen, thrombin-antithrombin complex, tissue plasminogen activator, plasminogen activator inhibitor 1 , platelet aggregation, or factor VIII.

5. Published at the date of the searches.

We excluded articles that were ahead of print and those that used the effect of resistance training as a variable in experimental hemostasis associated or compared with other forms of exercise (aerobic training), food intake, fluids, and the use of devices (restricting the blood flow by sphygmomanometer tourniquet) but did not use the resistance training as a primary dependent variable.

\section{Results}

Seventeen studies were found during the research process. Of these, ten articles were excluded (one article was in Turkish, three included food intake, one included water intake, three used vascular occlusion, one article included a combination of resistance training with aerobic training, and one compared resistance training with aerobic training).

Thus, seven studies were selected for analysis. The main findings of the studies involving resistance training and hemostasis are summarized in Table 1.

\section{Blood hemostasis: general overview}

Hemostasis is achieved by a delicate balance between the coagulation and fibrinolysis (a process by which fibrin is dissolved into soluble components) systems. ${ }^{1}$ Normal hemostasis is the result of a well-regulated set of processes that perform two important functions: ${ }^{21}$ keeping the blood in a fluid state and free from clots in normal vessels and inducing a rapid and localized hemostatic plug at the vascular injury site. In abnormal hemostasis, inappropriate blood clotting occurs to stop blood flow in the intravascular compartment. ${ }^{22}$

According to Porth, hemostasis is divided into five stages: (1) vascular spasm, (2) platelet plug formation, (3) blood clotting, (4) dissolving, and (5) clot retraction. ${ }^{22}$ The vascular spasm is triggered by the occurrence of cutting or endothelial disruption. Immediately after blood vessel damage or trauma to the vascular wall, the smooth muscles contract instantly to reduce blood flow to the injured vessel. Platelets cause much of the vasoconstriction by releasing a vasoconstrictor called tromboxano $\mathrm{A}_{2} \cdot{ }^{23}$

The development of the platelet plug is initiated by contact of the platelets with the injured vascular wall. This activates endothelial cells that serve primarily to inhibit platelet adhesion and blood clotting, resulting in a procoagulant phenotype and increasing clot formation. ${ }^{21}$ In this process, their characteristics change dramatically and they release active factors called "von Willebrand factors," which are sticky and adhere to the collagen and connective tissue protein and act on the neighboring platelets, in turn activating those platelets and sticking them to the platelets originally activated..$^{23}$ These phenomena are also observed during intense exercise, but they affect the platelet function differently. ${ }^{24}$ The influence of shear stress or a disturbance of the laminar blood flow promoted by high-intensity exercise may increase the risk of arterial vascular thrombosis, in which the platelet adhesion is proportional to the magnitude of the change in the blood flow. ${ }^{25}$ In the third mechanism, the clot begins to develop between 15 and 20 seconds after 
Table I Short-term effects of resistance training on hemostasis in healthy individuals

\begin{tabular}{|c|c|c|c|c|}
\hline Authors & Age in years (SD) & Training protocol & $\begin{array}{l}\text { Hemostatic } \\
\text { variables }\end{array}$ & Results \\
\hline El-Sayed ${ }^{33}$ & $\begin{array}{l}25(3.2)^{\mu} \\
\$ 6 \mathrm{men} / \mathrm{I} \text { woman }^{\$}\end{array}$ & $\begin{array}{l}\text { Protocol I: I-5 reps, } \\
90 \%-100 \% \text { I RM; }{ }^{\mathrm{R}} 60 \mathrm{~s} \\
\text { Protocol 2: 8-I2 reps, } \\
80 \% \text { IRM; }{ }^{\mathrm{R}} 30 \mathrm{~s} \\
\text { Both protocols with } \\
9 \text { exercises; } 5 \text { sets }\end{array}$ & $\begin{array}{l}\text { PAI-I, t-PA, } \\
\text { VIII/FVIII }\end{array}$ & $\begin{array}{l}\text { t-PA (HV vs LV) =@ } \uparrow ; \text { PAI-I } \\
(H V \text { vs LV) }=@ \downarrow ; \text { VIII/FVIII } \\
(H V \text { vs LV) }=@ \uparrow\end{array}$ \\
\hline $\begin{array}{l}\text { Ahmadizad } \\
\text { and El-Sayed }{ }^{31}\end{array}$ & $\begin{array}{l}26(7.0)^{\mu} \\
13 \text { men; untrained }\end{array}$ & 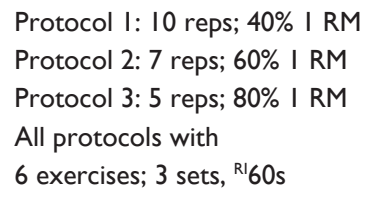 & $\begin{array}{l}\text { MPV, PCT, } \\
\text { PLT, B-TG }\end{array}$ & $\begin{array}{l}\text { MPV }(40 \%, 60 \% \text { and } 80 \%)=\mathrm{NS} ; \mathrm{PCT} \\
\text { and PLT }(40 \%, 60 \%, 80 \% \text { vs rest })= \\
@ \uparrow ; \text { B-TG }(80 \% \text { vs rest })=@ \downarrow\end{array}$ \\
\hline $\begin{array}{l}\text { Ahmadizad } \\
\text { and El-sayed } \\
\text { 32 }\end{array}$ & $\begin{array}{l}27(4.8)^{\mu} \\
10 \text { men; resistance trained } \\
\text { II men; untrained }\end{array}$ & $\begin{array}{l}\text { Protocol: } 5-7 \text { reps; } \\
80 \% \text { IRM; } 3 \text { sets; } \\
6 \text { exercises; } 3 \text { sets; }{ }^{\text {RI}} 60 \text { s }\end{array}$ & PLV, fibrinogen & PLV and fibrinogen (AE vs rest) $=@ \uparrow$ \\
\hline $\begin{array}{l}\text { Ahmadizad } \\
\text { et } \mathrm{al}^{30}\end{array}$ & $\begin{array}{l}27(4.8)^{\mu} \\
10 \text { men; resistance trained } \\
\text { II men; untrained }\end{array}$ & $\begin{array}{l}\text { Protocol: } 5-7 \text { reps; } 80 \% \text { I RM } \\
6 \text { exercises; } 3 \text { sets; }{ }^{\text {RI } 60 s}\end{array}$ & B-TG & $\begin{array}{l}\text { B-TG (rec vs rest) }=@ \uparrow ; \mathrm{B}-\mathrm{TG} \\
(\mathrm{AE} \text { vs rest) }=@ \uparrow\end{array}$ \\
\hline Dejong et $\mathrm{al}^{29}$ & $\begin{array}{l}57(9.0)^{\mu} \\
14 \text { men; untrained; } C A D^{\ddagger}\end{array}$ & $\begin{array}{l}\text { Protocol: } 10 \text { reps; } 10 \text { RMs } \\
8 \text { exercises; I sets; }{ }^{\mathrm{R}} 60 \mathrm{~s}\end{array}$ & $\begin{array}{l}\text { PAI-I, t-PA, } \\
\text { FvW }\end{array}$ & $\begin{array}{l}\mathrm{FvW}=\mathrm{NS} ; \mathrm{t}-\mathrm{PA}(\mathrm{AE} \text { vs rest })=@ \uparrow ; \\
\mathrm{PA}-\mathrm{I}(\mathrm{A} E \text { vs rest) }=@ \downarrow \downarrow \text { PA-I } \\
\text { (recup vs rest)= @ } \downarrow\end{array}$ \\
\hline $\begin{array}{l}\text { Nagelkirk } \\
\text { et } \mathrm{al}^{27}\end{array}$ & $\begin{array}{l}* 23(5.0)^{\mu} \\
8 \text { women; untrained; } \\
\text { low body fat } \\
8 \text { women; untrained; } \\
\text { high body fat }\end{array}$ & $\begin{array}{l}\text { Protocol: I0 reps; } 70 \% \text { I RM } \\
\text { I exercises; } 6 \text { sets; }{ }^{\text {RI }} \text { I20s }\end{array}$ & $\begin{array}{l}\text { TAT, t-PA, } \\
\text { PAI-I }\end{array}$ & $\begin{array}{l}\text { t-PA in HF and LF (rec vs rest) }=@ \downarrow ; \\
\text { PAI- I in rest (HF vs LF) }=@ \uparrow ; \\
\text { TAT (HF vs LF) }=\text { NS }\end{array}$ \\
\hline $\begin{array}{l}\text { Ahmadizad } \\
\text { et } \mathrm{a}^{28}\end{array}$ & $\begin{array}{l}29(4.5)^{\mu} \\
10 \text { men; untrained }\end{array}$ & $\begin{array}{l}\text { Protocol: } 7 \text { reps; } 80 \% \text { I RM } \\
6 \text { exercises; } 3 \text { sets; }{ }^{\mathrm{R}} 60 \mathrm{~s}\end{array}$ & B-TG e PA & $\begin{array}{l}\text { PA (morning rest vs evening rest) }=@ \uparrow ; \\
\text { B-TG (morning vs evening) = NS; B-TG } \\
(\text { AE morning and evening vs rest) }=@ \uparrow\end{array}$ \\
\hline \multicolumn{5}{|c|}{ 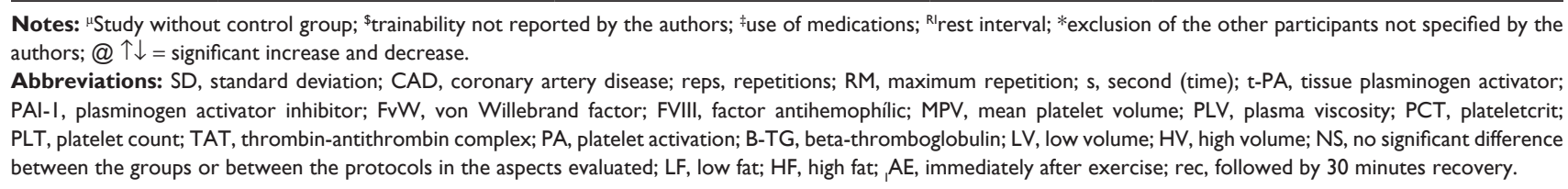 } \\
\hline
\end{tabular}

the injury to the vascular wall if the trauma is severe and between 1 and 2 minutes after the injury if the trauma is minor. $^{23}$

Depending on its intensity, exercise can either accelerate clot formation or lead to the dissolution of clot formation (fibrinolysis). ${ }^{26} \mathrm{~A}$ few minutes after clot formation occurs, the muscles retract, expelling the whey and uniting the edges of the injured vessel, contributing to the final stage of hemostasis. ${ }^{22}$

\section{Blood coagulation pathways}

According to El-Sayed et al, ${ }^{2}$ the activation of blood coagulation is the result of the formation of thrombin and, ultimately, the formation of fibrin. The key function of thrombin is to convert soluble fibrinogen into insoluble fibrin. ${ }^{2}$

The main pathway of clot activation is the extrinsic pathway although both routes are involved in the formation of a platelet plug. In physiologic situations, the intrinsic pathway seems to be only a supplement. ${ }^{26}$

The intrinsic pathway is initiated when contact is made between the blood and the exposed endothelial surfaces, and the extrinsic route is initiated by vascular injury, leading to the exposure of tissue. ${ }^{22,23}$ Although they are initiated by different mechanisms, both pathways lead to the formation of a platelet plug, and both are complex and involve numerous different proteins called "clotting factors."

\section{Hemostasis and resistance training: short-term effects}

The methodologies employed in the related studies were heterogeneous, showing that changes occurred according to exercise, ${ }^{27,28}$ clinical status and age of the participants, ${ }^{29}$ experience in resistance training, ${ }^{30,31}$ gender, ${ }^{32}$ hemostatic variables analyzed, ${ }^{31,33}$ and intensities. ${ }^{29,33}$ However, the rest 
interval between sets and the type of intervention showed little variation (between 30- and 60-second intervals; all protocols were short-term).

El-Sayed was the pioneer in investigating the effect of resistance training and the variables of resistance training on volume in the hemostatic and fibrinolytic system. ${ }^{33}$ In the study, six healthy men and one healthy woman performed three experimental conditions, separated by 7 days. The first condition was the control, the second condition was performed using a low volume protocol, and the third condition was performed using a high-volume (HV) protocol (Table 1).

The results of this study showed increased fibrinolysis (tissue plasminogen activator) in response to both protocols. However, the fibrinolytic response was significantly higher with the HV protocol when compared with the low volume protocol. The HV protocol showed a significantly lower response of plasminogen activator inhibitor 1 than was elicited during the low-volume protocol. The VIII/FVIII showed a significant increase after exercise and its magnitude depended on the volume of the training, being higher for the HV protocol.

Ahmadizad and El-Sayed ${ }^{31}$ determined the effects of the intensity of resistance training on platelet function and activation in 13 healthy men. The participants performed the resistance training on three different days at different intensities separated by 7 days (Table 1). The results showed no significant difference in the mean platelet volume of the three conditions analyzed. The platelet count and plateletcrit were significantly higher in the three conditions compared with rest. The beta-thromboglobulin was significantly higher only with intensities of $80 \%$ of 1 maximum repetition (RM) when compared with rest.

Ahmadizad and El-Sayed ${ }^{32}$ examined the short-term change on blood rheological variables after a single session of resistance training in 21 healthy men (Table 1) and concluded that plasma viscosity and fibrinogen were significantly higher immediately after exercise when compared with rest.

Ahmadizad et $\mathrm{al}^{30}$ investigated the effect of a resistance training session on the platelet activation and platelet function during training and recuperation. The study included 21 healthy men who completed the resistance training at an intensity corresponding to $80 \%$ of 1 RM (Table 1 ). They concluded that high-intensity resistance training induces platelet activation that is manifested by a significant increase in beta-thromboglobulin after the exercise, but this effect decreased significantly on recuperation, although it remained significantly different from the resting values.

DeJong et $\mathrm{al}^{29}$ evaluated the hemostatic and fibrinolytic responses to acute resistance training in patients with coronary artery disease. The study included 14 men with coronary artery disease and each participant performed a session of 10 RMs (Table 1). The results showed that tissue plasminogen activator increased and plasminogen activator inhibitor 1 decreased after training. However, the reduction in plasminogen activator inhibitor 1 persisted significantly for an hour after training. They concluded that a session of resistance training induced acute improvements in the fibrinolytic system (tissue plasminogen activator) in men with coronary artery disease without elevating potential thrombotic markers.

Ahmadizad et $\mathrm{al}^{28}$ investigated the interaction between the time of day and resistance training on platelet activation (Table 1). The study included ten healthy men who performed resistance training on two different occasions ( 8 am and $8 \mathrm{pm}$ ) followed by a 30-minute recovery. Results showed that the platelet activation at rest was significantly increased in the morning session and not in the evening trials. They also found a significant difference in beta-thromboglobulin immediately post-exercise but with no difference between the trials.

Nagelkirk et $\mathrm{al}^{27}$ evaluated the coagulation and fibrinolytic response to resistance training in 23 healthy women and determined the influence of body compositions on these responses, separating them into low and high-fat percentages (Table 1). Results revealed that tissue plasminogen activator significantly decreased after training for both groups but body composition modulates this response and the increase was less for the group with the highest percentage of fat. Participants with a lower percentage of fat exhibited significantly lower levels of plasminogen activator inhibitor 1 in the pretest than participants with the highest percentage of fat, but there was no significant difference in the posttest.

\section{Discussion}

We conclude that there are apparent indications that resistance training induces changes in the hemostatic system to a fibrinolytic blood profile and these changes depend on the training intensity and volume. However, the present review indicates that the effects in the concluded studies were controversial, which reinforces the importance of future randomized controlled trials to better understand the effects of resistance training on hemostasis. It also reinforces the importance of future randomized controlled trials to better understand the effects of resistance training on hemostasis.

The young adults in the protocol using HV training showed a greater fibrinolytic response and the training protocols with intensities above $80 \%$ of $1 \mathrm{RM}$ induced greater platelet activity as assessed by beta-thromboglobulin. 
In subjects with coronary artery disease, just one session of resistance training with a set of ten repetitions resulted in improvement in the fibrinolytic system (tissue plasminogen activator) without raising potential thrombotic markers (plasminogen activator inhibitor). However, more studies are needed to better understand the effect of this type of exercise on hemostatic parameters. Health professionals such as cardiologists should consider resistance training as an aid in the treatment, prevention, and rehabilitation of cardiovascular disease and circulatory problems.

\section{Limitations of the study}

As the transparency of this review evidencing the intervention of resistance training and effectiveness in hemostasis is impaired, it should be interpreted with caution. ${ }^{34}$ Further, the small number of studies reviewed here do not offer a firm conclusion regarding the positive effects of resistance training on hemostasis.

The composition of the samples in the studies, including young people with and without experience in resistance training, age, and gender, as well as the composition of the control groups, should also be considered.

Finally, another potential limitation is that the identification of relevant publications was performed by the author, and therefore has the potential for subjectivity.

\section{Conclusion}

Given the variety of studies and the controversial results, practitioners and researchers need to be aware that the results presented above are based on limited evidence. The protocols using an $\mathrm{HV}$ of training for young adults showed a greater fibrinolytic response, and training protocols with intensities above $80 \%$ of $1 \mathrm{RM}$ showed greater platelet activity. In subjects with coronary artery disease, just one session of resistance training resulted in improvement in the fibrinolytic system (tissue plasminogen activator) without raising potential thrombotic markers. To better understand the possible benefits of resistance training on hemostasis, further research is necessary. Future studies should examine the chronic effects of resistance training on hemostatic parameters.

In addition, the number of participants in the studies analyzed was small; therefore, future research requires a representative sample of the general population. Comparisons between genders and the effect of resistance training on hemostatic parameters in different populations (hypertensive and obese patients with metabolic syndrome) should be taken into consideration.

\section{Acknowledgments}

The author would like to thank João Henrique Leão Veloso, $\mathrm{MD}$, for initial writing assistance.

\section{Disclosure}

The authors report no conflicts of interest in this work.

\section{References}

1. Smith JE. Effects of strenuous exercise on haemostasis. Br J Sports Med. 2003;37(5):433-435.

2. El-Sayed MS, Sale C, Jones PG, Chester M. Blood hemostasis in exercise and training. Med Sci Sports Exerc. 2000;32(5):918-925.

3. Newby DE, Wright RA, Labinjoh C, et al. Endothelial dysfunction, impaired endogenous fibrinolysis, and cigarette smoking: a mechanism for arterial thrombosis and myocardial infarction. Circulation. 1999;99(11):1411-1415.

4. Yang P, Liu YF, Yang L, Wei Q, Zeng H. Mechanism and clinical significance of the prothrombotic state in patients with essential hypertension. Clin Cardiol. 2010;33(6):E81-E86.

5. Grant PJ. Diabetes mellitus as a prothrombotic condition. J Intern Med. 2007;262(2):157-172.

6. Thijssen DH, Maiorana AJ, O’Driscoll G, Cable NT, Hopman MT, Green DJ. Impact of inactivity and exercise on the vasculature in humans. Eur J Appl Physiol. 2010;108(5):845-875.

7. Bucciarelli P, Mannucci PM. The hemostatic system through aging and menopause. Climacteric. 2009;12 Suppl 1:47-51.

8. Ghisi GL, Durieux A, Pinho R, Benetti M. Physical exercise and endothelial dysfunction. Arq Bras Cardiol. 2010;95(5):e130-e137.

9. Sugawara J, Hayashi K, Kurachi S, Tanaka T, Yokoi T, Kurachi K. Age-related effects of regular physical activity on hemostatic factors in men. J Thromb Thrombolysis. 2008;26(3):203-210.

10. Koenig W, Ernst E. Exercise and thrombosis. Coron Artery Dis. 2000;11(2):123-127.

11. Di Francescomarino S, Sciartilli A, Di Valerio V, Di Baldassarre A, Gallina S. The effect of physical exercise on endothelial function. Sports Med. 2009;39(10):797-812.

12. Umpierre D, Stein R. Hemodynamic and vascular effects of resistance training: implications for cardiovascular disease. Arq Bras Cardiol. 2007;89(4):256-262.

13. Kelley GA, Kelley KS. Progressive resistance exercise and resting blood pressure: A meta-analysis of randomized controlled trials. Hypertension. 2000;35(3):838-843.

14. SciVerse Scopus [database on the Internet]. Amsterdam: Elsevier; 2011. Available from: http://www.scopus.com/home.url. Accessed February 7, 2012.

15. MEDLINE ${ }^{\circledR}$ [database on the Internet]. Bethesda, MD: National Library of Medicine; nd. Available from: http://www.ncbi.nlm.nih. gov/pubmed/. Accessed February 7, 2012.

16. SciELOBrazil [database on the Internet]. San Paulo: SciELO; nd. Available from: http://www.scielo.org/php/index.php?lang=en. Accessed February 7, 2012.

17. LILACS [database on the Internet]. San Paulo: Latin American and Caribbean Center on Health Sciences Information; nd. Available from: http://bases.bireme.br/cgi-bin/wxislind.exe/iah/online/?IsisScript=iah/ iah.xis\&base=LILACS\&lang=i\&form=F. Accessed February 7, 2012.

18. IBECS [database on the Internet]. San Paulo: Latin American and Caribbean Center on Health Sciences Information; nd. Available from: http://ibecs.isciii.es/cgi-bin/wxislind.exe/iah/online/?IsisScript=iah/ iah. $x$ is \&base $=$ IBECS\&lang $=\mathrm{i} \&$ form $=$ F. Accessed February 7, 2012.

19. The Cochrane Library [database on the Internet]. Hoboken, NJ: John Wiley and Sons; 2010. Available from: http://www.thecochranelibrary. com/view/0/index.html. Accessed February 7, 2012. 
20. MeSH [database on the Internet]. Bethesda, MD: National Library of Medicine; 2011 [updated August 28]. Available from: http://www.nlm. nih.gov/mesh/MBrowser.html. Accessed February 7, 2012.

21. Kumar V, Cotran RS, Robbins SL, editors. Robbins Basic Pathology. 7th ed. Philadelphia, PA: Saunders; 2003.

22. Porth C. Pathophysiology: Concepts of Altered Health States. 6th ed. Philadelphia: Lippincott Williams \& Wilkins; 2002.

23. Guyton AC, Hall JE. Textbook of Medical Physiology. 11th ed. Philadelphia: Elsevier Saunders; 2006.

24. Wang JS, Jen CJ, Kung HC, Lin LJ, Hsiue TR, Chen HI. Different effects of strenuous exercise and moderate exercise on platelet function in men. Circulation. 1994;90(6):2877-2885.

25. Wang JS. Intense exercise increases shear-induced platelet aggregation in men through enhancement of von Willbrand factor binding, glycoprotein IIb/IIIa activation, and P-selectin expression on platelets. Eur J Appl Physiol. 2004;91(5-6):741-747.

26. El-Sayed MS, El-Sayed Ali Z, Ahmadizad S. Exercise and training effects on blood haemostasis in health and disease: an update. Sports Med. 2004;34(3):181-200.

27. Nagelkirk PR, Scalzo R, Harber M, Kaminsky LA. The influence of acute resistance training and body composition on coagulation and fibrinolytic activity in low-risk women. Int J Sports Med. 2010;31(7):458-462.
28. Ahmadizad S, El-Sayed MS, MacLaren DP. Effects of time of day and acute resistance exercise on platelet activation and function. Clin Hemorheol Microcirc. 2010;45(2-4):391-399.

29. deJong AT, Womack CJ, Perrine JA, Franklin BA. Hemostatic responses to resistance training in patients with coronary artery disease. J Cardiopulm Rehabil. 2006;26(2):80-83.

30. Ahmadizad S, El-Sayed MS, Maclaren DP. Responses of platelet activation and function to a single bout of resistance exercise and recovery. Clin Hemorheol Microcirc. 2006;35(1-2):159-168.

31. Ahmadizad S, El-Sayed MS. The effects of graded resistance exercise on platelet aggregation and activation. Med Sci Sports Exerc. 2003;35(6):1026-1032.

32. Ahmadizad S, El-Sayed MS. The acute effects of resistance exercise on the main determinants of blood rheology. J Sports Sci. 2005;23(3):243-249.

33. El-Sayed MS. Fibrinolytic and hemostatic parameter response after resistance exercise. Med Sci Sports Exerc. 1993;25(5):597-602.

34. Liberati A, Altman DG, Tetzlaff J, et al. The PRISMA statement for reporting systematic reviews and meta-analyses of studies that evaluate health care interventions: explanation and elaboration. $B M J$. 2009;339:b2700.
International Journal of General Medicine

\section{Publish your work in this journal}

The International Journal of General Medicine is an international, peer-reviewed open-access journal that focuses on general and internal medicine, pathogenesis, epidemiology, diagnosis, monitoring and treatment protocols. The journal is characterized by the rapid reporting of reviews, original research and clinical studies across all disease areas.

\section{Dovepress}

A key focus is the elucidation of disease processes and management protocols resulting in improved outcomes for the patient. The manuscript management system is completely online and includes a very quick and fair peer-review system. Visit http://www.dovepress.com/ testimonials.php to read real quotes from published authors. 